\title{
Mechanisms Affecting the Overturning Response in Global Warming Simulations
}

\author{
U. SCHWECKENDIEK AND J. WILLEBRAND \\ Leibniz-Institut für Meereswissenschaften, Kiel, Germany
}

(Manuscript received 8 November 2004, in final form 19 May 2005)

\begin{abstract}
Climate models used to produce global warming scenarios exhibit widely diverging responses of the thermohaline circulation (THC). To investigate the mechanisms responsible for this variability, a regional Atlantic Ocean model driven with forcing diagnosed from two coupled greenhouse gas simulations has been employed. One of the coupled models (MPI) shows an almost constant THC, the other (GFDL) shows a declining THC in the twenty-first century.

The THC evolution in the regional model corresponds rather closely to that of the respective coupled simulation, that is, it remains constant when driven with the forcing from the MPI model, and declines when driven with the GFDL forcing. These findings indicate that a detailed representation of ocean processes in the region covered by the Atlantic model may not be critical for the simulation of the overall THC changes in a global warming scenario, and specifically that the coupled model's rather coarse representation of water mass formation processes in the subpolar North Atlantic is unlikely to be the primary cause for the large differences in the THC evolution.

Sensitivity experiments have confirmed that a main parameter governing the THC response to global warming is the density of the intermediate waters in the Greenland-Iceland-Norwegian Seas, which in turn influences the density of the North Atlantic Deep Water, whereas changes in the air-sea heat and freshwater fluxes over the subpolar North Atlantic are only of moderate importance, and mainly influence the interannual-decadal variability of THC.

Finally, as a consequence of changing surface fluxes, the Labrador Sea convection ceases by about 2030 under both forcings (i.e., even in a situation where the overall THC is stable) indicating that the eventual breakdown of the convection is likely but need not coincide with substantial THC changes.
\end{abstract}

\section{Introduction}

The Atlantic thermohaline circulation (THC) is an important element of the climate system, and its behavior in future climate conditions influenced by global warming is therefore of great interest. Most global warming scenario calculations with coupled oceanatmosphere models suggest a decrease of the THC strength over the coming century. However, the differences between different models are considerable (Houghton et al. 2001), and while some models predict a more or less complete shutdown of the THC (e.g., Manabe and Stouffer 1994), others predict little change (Latif et al. 2000; Gent 2001).

In most models, surface warming and to a lesser ex-

Corresponding author address: Dr. U. Schweckendiek, LeibnizInstitut für Meereswissenschaften, Düsternbrooker Weg 25, D-24105 Kiel, Germany.

E-mail: uschweckendiek@ifm-geomar.de tent freshening in regions of water mass formation is responsible for the weakening of the THC. In those calculations where a stabilization of the THC occurs, it is related to increasing surface salinities that counteract surface density loss through heating. The mechanisms for that salinity increase are however rather different. Gent (2001) reported locally enhanced evaporation in regions of deep-water formation in the Community Climate System Model (CCSM), with the THC responding to local atmospheric forcing in a more or less passive way as discussed by (e.g., Delworth and Greatbatch 2000). In contrast, in the ECHAM4/OPYC3 coupled model the enhanced evaporation occurs in the Tropics and subtropics, and the resulting high salinity signal is ultimately advected into convective regions (Latif et al. 2000). Thorpe et al. (2001) found a similar but weaker salt advection stabilizing the THC at a lower level. These latter simulations suggest a more active role of the ocean in the response of the THC.

To the extent that lateral transports of water with 
realistic water mass properties are relevant to predict changes in deep-water formation and hence of the THC, the representation of the ocean circulation in climate models is of crucial importance. Coupled climate models can simulate the right magnitudes for the largescale transports of heat and freshwater. However, as a consequence of their coarse resolution they lack a proper representation of boundary currents and other important small- and mesoscale processes, including aspects of the water mass transformation processes that are crucial for the thermohaline circulation. The deep western boundary current, which forms the principal return branch of the THC, consists of three main water masses: the Denmark Strait Overflow Water, the Iceland-Scotland Overflow Water, and the Labrador Sea Deep Water (e.g., Fischer and Schott 1997). Many coupled climate models have difficulties in simulating the correct location, rate, and mechanisms of formation and properties of these water masses (cf. the discussion by Jia 2002).

Such deficits can affect the simulation not only of the mean THC but also of the THC response to changing atmospheric conditions. For example, Döscher and Redler (1997) found that when the small-scale density signal associated with the Denmark Strait Overflow is lacking, the sensitivity of the THC to surface forcing within the subpolar gyre is overly strong. They concluded that coarse resolution models that are unable to simulate these small-scale flows may overestimate the response of the THC on decadal time scales. As another example, the variability of the air-sea heat flux over the Labrador Sea is mainly responsible for interannual variability of the THC in the model study of Eden and Willebrand (2001), and it is obvious that models that do no properly represent the Labrador Sea convection should not be relied on to correctly simulate THC variability on interannual time scales.

The purpose of this study is to investigate the ocean mechanisms responsible for long-term changes of the overturning circulation, and in particular the question to what extent are the differing responses of coupled climate models in global warming simulations related to deficits in the representation of ocean dynamics. Our strategy is to employ a regional ocean model that is well tested with respect to the relevant processes of water mass formation, and can simulate circulation and water mass distribution in the North Atlantic fairly realistically. The regional model is driven by flux changes from two global coupled simulations with rather different behavior. In addition to evaluating the overall response of the regional model, sensitivity studies with selected components of the forcing are performed, which allow for the identification of relevant mechanisms.
The paper is organized as follows. In section 2, a brief description of the regional ocean model as well as the two coupled climate models is given, and the implementation of anthropogenic forcing in the regional model is described. The results are discussed in section 3 where we concentrate on the different sources for overturning variability and the specific response within the Labrador Sea. The conclusions are summarized in section 4.

\section{Model aspects}

\section{a. The regional ocean model}

The regional ocean model used in this study is part of the Family of Linked Atlantic Model Experiments (FLAME), a modeling effort based on the Geophysical Fluid Dynamics Laboratory (GFDL) Modular Ocean Model version 2.1 (MOM 2.1) z-coordinate primitive equation model (Pacanowski 1995). The model has a horizontal resolution of $4 / 3^{\circ} \times 4 / 3 \cos (\phi)$ and 45 vertical levels, with nine levels in the upper $100 \mathrm{~m}$. In this configuration the model has been used for studies concerning the mean state and variability within the Atlantic Ocean (e.g., Eden and Willebrand 2001; Eden and Jung 2001).

The influence of mesoscale eddies on the circulation is parameterized with the (Gent and McWilliams 1990) scheme. For the representation of processes in the bottom boundary layer (BBL), particularly for overflows, a parameterization for the density-driven downslope flow was used (Döscher and Beckmann 2000).

The model region extends from $70^{\circ} \mathrm{S}$ to $70^{\circ} \mathrm{N}$ and from $100^{\circ} \mathrm{W}$ to $16^{\circ} \mathrm{E}$. The northern and southern boundaries are closed, with zones of restoring to monthly mean climatological data. At the eastern and western boundaries in the Southern Ocean, open boundary conditions according to (Stevens 1990) are used, and on inflow points a barotropic streamfunction and temperature/salinity are prescribed. For the control run, surface boundary conditions and all model parameters are identical to Eden and Willebrand (2001). Specifically, the surface heat flux $Q_{\text {ctrl }}$ is coupled to the model surface temperature $T_{\text {ctrl }}$ via a Haney-type boundary condition (Haney 1971):

$$
Q_{\mathrm{ctrl}}=Q_{0}+\lambda\left(T_{0}-T_{\mathrm{ctrl}}\right) .
$$

Here $Q_{0}$ and $T_{0}$ represent climatological heat flux and SST, respectively, and $\lambda$ is a spatially and temporally varying coupling parameter with typical values around $40 \mathrm{~W} \mathrm{~m}^{-2} \mathrm{~K}^{-1}$. To obtain the freshwater fluxes, a $50-\mathrm{yr}$ spinup was performed where sea surface salinity was 
restored toward the combined Levitus and Boyer (1994) and Boyer and Levitus (1997) climatologies with a 15-day time scale. Subsequently, monthly mean freshwater fluxes $F_{\text {ctrl }}$ were calculated as average over the last $10 \mathrm{yr}$ of the spinup. In the following control run with mixed boundary conditions, the basinwide salinity drift is less than $0.01 \mathrm{psu}$ in $150 \mathrm{yr}$.

The annual mean overturning function obtained from the regional model with climatological forcing has a maximum strength of about $16 \mathrm{~Sv}\left(1 \mathrm{~Sv} \equiv 10^{6} \mathrm{~m}^{3} \mathrm{~s}^{-1}\right)$ localized at $40^{\circ} \mathrm{N}$. In the Labrador Sea deep-water formation sets in and reaches a depth of about $2000 \mathrm{~m}$ during March. The Denmark Strait Overflow has a transport of about $3 \mathrm{~Sv}$ below $\sigma_{\Theta}=27.75 \mathrm{~kg} \mathrm{~m}^{-3}$. Due to the temperature and salinity restoring at the northern boundary, the water mass properties in that region are fairly realistic.

\section{b. The climate models}

We have analyzed greenhouse simulations with two different coupled models, the Max-Planck Institute (MPI) ECHAM4/OPYC3 (hereafter MPI; Bacher et al. 1998; Oberhuber et al. 1998; Latif et al. 2000) and the GFDL R30 (gps03; hereafter GFDL) (Dixon et al. 1999; Delworth et al. 2002). In both cases the $\mathrm{CO}_{2}$ level follows the IS92a global warming scenario (Houghton et al. 1992) until the years 2100 (MPI) respective 2090 (GFDL). In GFDL the direct effect of tropospheric sulfate aerosols is included as a modification of the surface albedo varying in time and space (Haywood et al. 1997).

The horizontal resolution of the MPI ocean component is $2.8^{\circ} \times 2.8^{\circ}$. In the Tropics the meridional resolution increases to $0.5^{\circ}$, thus permitting a rather realistic simulation of the ENSO phenomenon. Isopycnal coordinates with 11 layers are used. The configuration of MPI in its greenhouse warming scenario is described in Bacher et al. (1998).

The ocean component of GFDL is the GFDL MOM$1.1 z$-coordinate primitive equation model (Pacanowski et al. 1991). The horizontal resolution is $2.25^{\circ}$ latitude $\times 1.875^{\circ}$ longitude with 18 unevenly spaced vertical levels. The gps03 scenario, which is used for this study is described in Delworth et al. (2002).

Relative to the regional ocean model both coupled models show deficits concerning circulation and water mass properties. Due to the idealized representation of the Denmark Strait and the Iceland-Scotland Overflow in MPI, the transport from the Greenland-IcelandNorwegian (GIN) Seas communicated into the subpolar basin is at $17 \mathrm{~Sv}$. The better representation of the topography in the GFDL model leads to a more realistic transport of $4.5 \mathrm{~Sv}$ of dense water over the sills relative to the observed 3 Sv (e.g., Dickson et al. 1990). While in MPI the deep-water formation is principally localized within the Nordic Seas, GFDL shows deep convection mainly south of Iceland and not in the central Labrador Sea. Other deficits in the representation of the North Atlantic concern the width or even existence of boundary currents (e.g., in MPI no west Greenland and Labrador Current can be observed).

At the end of the integration period, the global mean SST is $2.8^{\circ}$ warmer in GFDL and $2.2^{\circ}$ warmer in MPI relative to the mean between 1900 and 1950, indicating a somewhat larger climate sensitivity of the GFDL model. Since in this study we concentrate on processes affecting the overturning circulation, the local response in regions of deep-water formation is important. While in the high northern latitudes (Nordic Seas) the final warming is stronger in GFDL than in MPI, in the Labrador Sea region, MPI is $2.5^{\circ} \mathrm{C}$ warmer compared to $1.3^{\circ} \mathrm{C}$ warmer in GFDL. Since in both models the anthropogenic trend in surface heat flux is very similar, lateral ocean heat transports from lower latitudes might be the reason for the stronger warming in MPI in the western subpolar Atlantic. Indeed, inspection of the surface circulation in MPI suggests that the Gulf Stream extension reaches into the Labrador Sea.

While before 1950 both models have a mean overturning strength in the North Atlantic of about $25 \mathrm{~Sv}$, their response to the increasing $\mathrm{CO}_{2}$ level differs fundamentally (Fig. 1, in MPI and GFDL). In MPI the overturning circulation maintains its strength under anthropogenic forcing (Latif et al. 2000), while in GFDL the overturning declines by about $25 \%$ from 1950 to 2090 (Dixon et al. 2002).

\section{c. Implementation of anthropogenic forcing}

The sea surface temperatures and the fluxes of heat, freshwater, and momentum diagnosed from the integrations with both coupled climate models have been linearly interpolated to the regional ocean model's grid. Only the anomalies relative to the climatological mean state from 1860 to 1950 have been considered, in order to focus on the changes under global warming conditions.

Our concept is to integrate the regional model with its own (and proven) forcing on which the changes from the global warming scenario are superimposed. Hence the fluxes of freshwater $(F)$ and momentum $(\tau)$ are constructed as sum of the respective fluxes from the control run (index ctrl) and the flux anomalies from the coupled models (index gw):

$$
\begin{gathered}
F=F_{\mathrm{ctrl}}+F_{\mathrm{gw}}, \\
\tau=\tau_{\mathrm{ctrl}}+\tau_{\mathrm{gw}} .
\end{gathered}
$$




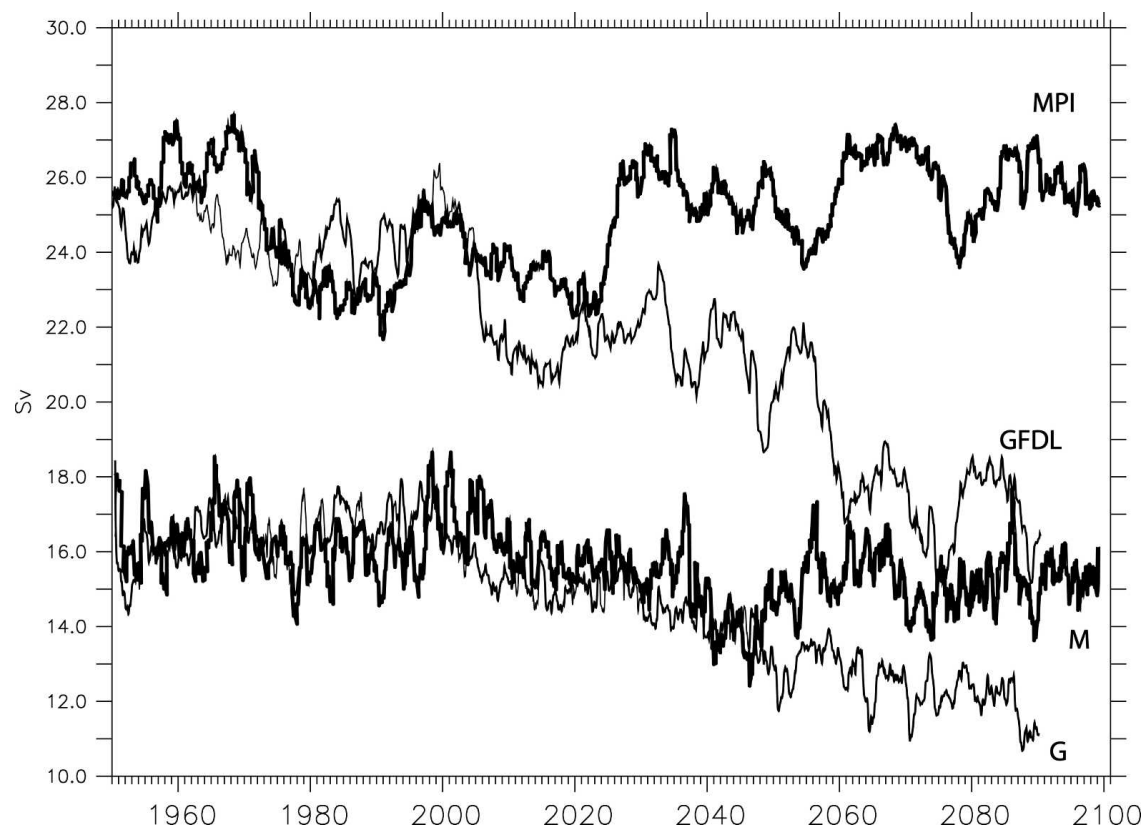

FIG. 1. The 1-yr running mean overturning index for the MPI climate model, the GFDL climate model, and the FLAME4/3 regional ocean model in experiments M and G (Sv).

For the heat flux $Q$, the situation is slightly more complicated due to the coupling of the heat flux to the surface temperature. Analogous to (1), the boundary condition is formulated as

$$
Q=Q_{0}+Q_{\mathrm{gw}}+\lambda\left(T_{0}+T_{\mathrm{gw}}-T\right),
$$

where $T$ is the model surface temperature. The effective change in heat flux relative to the control run is hence given by

$$
Q-Q_{\text {ctrl }}=Q_{\mathrm{gw}}+\lambda T_{\mathrm{gw}}-\lambda\left(T-T_{\mathrm{ctrl}}\right) .
$$

The balance in (5) is dominated by the restoring terms, and as a consequence, the surface temperature changes in the coupled model $\left(T_{\mathrm{gw}}\right)$ and in the regional model $\left(T-T_{\text {ctrl }}\right.$ ) coincide very closely (within $\sim 0.01^{\circ} \mathrm{C}$ in the basin mean). The effective flux changes are therefore not identical (e.g., for the final year in experiment $\mathrm{G}$, where $T_{\mathrm{gw}}=1.3^{\circ} \mathrm{C}$ we find $Q-Q_{\mathrm{ctrl}}=2.68 \mathrm{~W} \mathrm{~m}^{-2}$ and $Q_{\mathrm{gw}}=3.06 \mathrm{~W} \mathrm{~m}^{-2}$ as basin averages). Hence, the net heat uptake of the regional model in the final year is on average $0.37 \mathrm{~W} \mathrm{~m}^{-2}$ less than that of the climate model. The reason for this difference is of course the different evolution of the surface circulation in the regional model.

The restoring term for temperature and salinity at open vertical boundaries is formulated in an analogous way; for example, for temperature it is

$$
R^{T}=\gamma\left(T_{0}+T_{\mathrm{gw}}-T\right) .
$$

Here, $T$ is the model's temperature at restoring points, $T_{0}$ denotes climatological restoring data, and $T_{\mathrm{gw}}$ is the anthropogenic temperature change from the coupled model runs. The spatially varying restoring scale $\gamma$ is again taken from Eden and Willebrand (2001), and is such that changes in the water mass properties at open vertical boundaries of the regional model are closely related to corresponding changes in the global model. If these changes were unrealistic as a consequence of deficits in the climate model, the regional model would then suffer from unrealistic vertical boundary forcing.

To study the impact of certain components of regional forcing, several sensitivity studies with different combinations of climatological and anthropogenic forcing are performed, which are listed in Table 1 . Changes in wind stress forcing are relatively small in both MPI and GFDL scenarios. Their impact on the overturning circulation on decadal to interdecadal time scales in the regional model is less than $5 \%$ relative to that of the anomalous heat and freshwater flux forcing and is not further discussed.

\section{Results}

\section{a. Overturning response}

Experiment $\mathrm{M}$ shows an almost complete maintenance of the conveyor circulation consistent with the coupled model (Fig. 1, MPI and M). In contrast, in experiment $\mathrm{G}$ a spindown of the thermohaline cell in 
TABLE 1 . Sensitivity studies performed with FLAME 4/3 under anthropogenic forcing diagnosed from the MPI and the GFDL climate model. Implemented is heat $(Q)$, freshwater $(F)$, and momentum flux $(\tau)$ forcing at the surface as well as temperature $\left(R^{T}\right)$ and salinity $\left(R^{S}\right)$ time series at the vertical boundaries. The vertical boundary conditions are separated into northern boundary conditions (North BCs) and nonnorthern boundary conditions. The $+(-)$ symbols represent anthropogenic (climatological) forcing in Eqs. (4)-(6). The salinity (temperature) restoring at the nonnorthern boundaries is anthropogenic, if the surface freshwater (heat flux) forcing is anthropogenic, otherwise climatological. The overturning change is averaged over the last $10 \mathrm{yr}$ and relative to the equilibrium state of $16 \mathrm{~Sv}$.

\begin{tabular}{|c|c|c|c|c|c|c|c|}
\hline \multirow[b]{2}{*}{ Name } & \multicolumn{3}{|c|}{ Surface } & \multicolumn{2}{|c|}{ North BC } & \multirow{2}{*}{$\begin{array}{c}\text { Forcing } \\
\text { from }\end{array}$} & \multirow{2}{*}{$\begin{array}{l}\text { Overturning } \\
\text { change } \\
\text { (SV) }\end{array}$} \\
\hline & $Q$ & $F$ & $\tau$ & $R^{T}$ & $R^{S}$ & & \\
\hline CTRL & - & - & - & - & - & - & 0,0 \\
\hline M & + & + & + & + & + & MPI & $-1,0$ \\
\hline M_HEAT & + & - & + & + & - & MPI & $-3,5$ \\
\hline M_NORTH_S & + & - & + & + & + & MPI & $-1,5$ \\
\hline G & + & + & + & + & + & GFDL & $-4,0$ \\
\hline G_SURF & + & + & + & - & - & GFDL & $-1,0$ \\
\hline G_NORTH & - & - & - & + & + & GFDL & $-3,0$ \\
\hline
\end{tabular}

the North Atlantic sets in (Fig. 1, G). Relative to the climatological state, the $25 \%$ weakening is quite similar to the response of the GFDL climate model. Although both climate models show well-known deficits in representing the mean oceanic state, in terms of predicting the THC strength for the twenty-first century the improvements included in the regional ocean model do not change the response significantly.

However, the variability in the regional ocean model is different. The interannual variability is higher in both integrations. This might be the consequence of a more realistic representation of the Labrador Sea, which is crucial for the variability of the overturning circulation on these time scales (e.g., Eden and Willebrand 2001). In contrast, on decadal to interdacadal time scales, variability in both climate models is higher. The reason is likely the absence of coupled interactions in the regional ocean model.

Figure 2 shows the anomalous salinity (A), temperature (B), and resulting $\sigma_{\Theta}(\mathrm{C})$ time series in the core of the Denmark Strait Overflow for experiments $M$ and G. Due to the configuration of our experiments, these time series are quite similar to those of the coupled models, since the northern restoring boundary condition prescribes changes in water mass properties relative to the coupled scenarios. In M, the salinity is nearly constant until the year 2020 with a variability of 0.02 $\mathrm{psu}$, before a strong rise sets in to $0.18 \mathrm{psu}$ at the end of the integration period. The salinity time series in $G$ shows a stronger variability of $0.06 \mathrm{psu}$. Until the year
2000 no significant trend can be diagnosed. Thereafter, in contrast to $\mathrm{M}$, the overflow salinity varies substantially on interannual to decadal time scales, but the long-term trend results in net freshening by $0.2 \mathrm{psu}$ in 2090. Both experiments show increasing temperatures, $1.8^{\circ} \mathrm{C}$ in $\mathrm{M}$ and $2.5^{\circ} \mathrm{C}$ in $\mathrm{G}$.

The resulting density in the overflow waters is consequently different in both experiments. While rising salinities together with moderate warming lead to an almost complete density compensation in $\mathrm{M}$, at the end of the integration period the density in $\mathrm{G}$ is strongly reduced by $0.4 \mathrm{~kg} \mathrm{~m}^{-3}$ due to warming and freshening. The connection of these time series with the overturning index will be discussed in the following section.

\section{b. Mechanisms for overturning changes}

To investigate the mechanisms determining the variability and trend of the overturning circulation, several sensitivity studies have been performed, in which we focused on different combinations of anthropogenic forcing.

Let us first consider experiment $\mathrm{M}$. The stable response of the overturning circulation in this experiment (Fig. 1a) has been traced back to strongly enhanced evaporation and as a consequence to a development of a salt anomaly in the Tropics and subtropics of the Atlantic Ocean in the coupled model. This salt signal is ultimately advected into northern regions and compensates for the reduction of surface density due to local heating and freshening (Latif et al. 2000). Changes in temperature and salinity in experiment M (Fig. 2) lead to an almost constant density in the Denmark Strait Overflow region in the regional ocean model. Warming sets in at the beginning of the twenty-first century. A few years later, increasing salinities compensate the density reduction. By calculating salinity budgets (not shown here) it is confirmed that this salinity gain is indeed the consequence of enhanced lateral transports, and not of changing surface fluxes.

To investigate the specific role of the salt advection for the ocean model, in experiment M_HEAT (cf. Table 1) all freshwater forcing anomalies were switched off. Figure 3 shows the response of the overturning index in experiments M_HEAT and M. Due to the temperature increase, the overturning circulation slows down (thick line), and at the end of the integration period it is significantly reduced by about $4 \mathrm{~Sv}$. The temperatures of the Denmark Strait Overflow rise like in the full forcing experiment (Fig. 2b) by $1.8^{\circ} \mathrm{C}$ during the twenty-first century, while the overflow salinities remain almost unchanged due to the climatological restoring at the northern boundary. Interannual variability is nearly unchanged compared to experiment $\mathrm{M}$, 

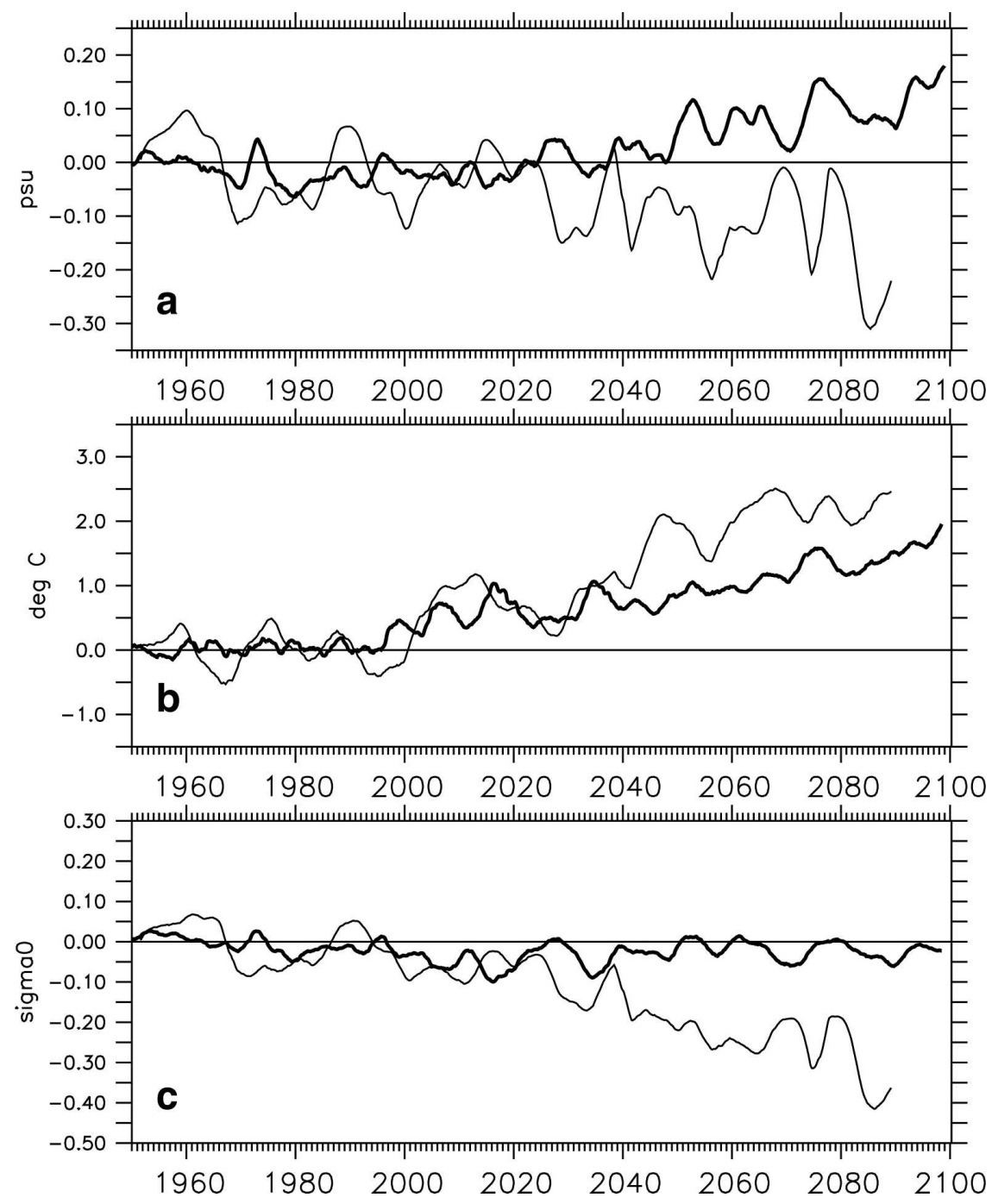

FIG. 2. The 2-yr running mean time series of anomalies in (a) salinity, (b) temperature, and (c) $\sigma_{\Theta}$ in the core of the Denmark Strait Overflow at $66^{\circ} \mathrm{N}, 32^{\circ} \mathrm{W}$ at $500-\mathrm{m}$ depth in experiments $\mathrm{M}$ (thick line) and $\mathrm{G}$ (thin line). In the $\mathrm{M}$ case, salinity changes compensate temperature changes, whereas in the $\mathrm{G}$ experiment, density is reduced due to heating and freshening.

confirming that the surface freshwater flux plays only a secondary role in generating interannual variability.

To find out in which region of the North Atlantic Ocean the salinity stabilization becomes effective, we performed experiment M_NORTH_S, which is identical to M_HEAT except that the climate model's salinity anomaly in the northern boundary condition is implemented. The enormous effect of this modification is shown in Fig. 3 (dashed line). The full forcing experiment (M) is almost totally reconstructed, indicating that increases in density in the overflow water are decisive for the evolution of the overturning, and that changes in surface freshwater forcing over the subpolar regions are less important. Only after year 2050, differences of the order of $1 \mathrm{~Sv}$ arise, which can be ascribed to northward salt transports in experiment $\mathrm{M}$, leading to increased surface salinities in the subpolar region, which enhance the overturning. This process is absent in experiment M_NORTH_S due to the lack of anomalous evaporation over the subtropics. This result demonstrates that in experiment $\mathrm{M}$ the stabilizing effect has become effective after the salt signal has entered the Nordic Seas and subsequently the overflow waters, pointing out the importance of changes in the overflow density for the THC.

The strong salt advection mechanism is absent in the GFDL model, and correspondingly we have found large differences in the Denmark Strait Overflow salinities and temperatures between the $\mathrm{M}$ and $\mathrm{G}$ integration (cf. Fig. 2). To investigate the role of the Nor- 


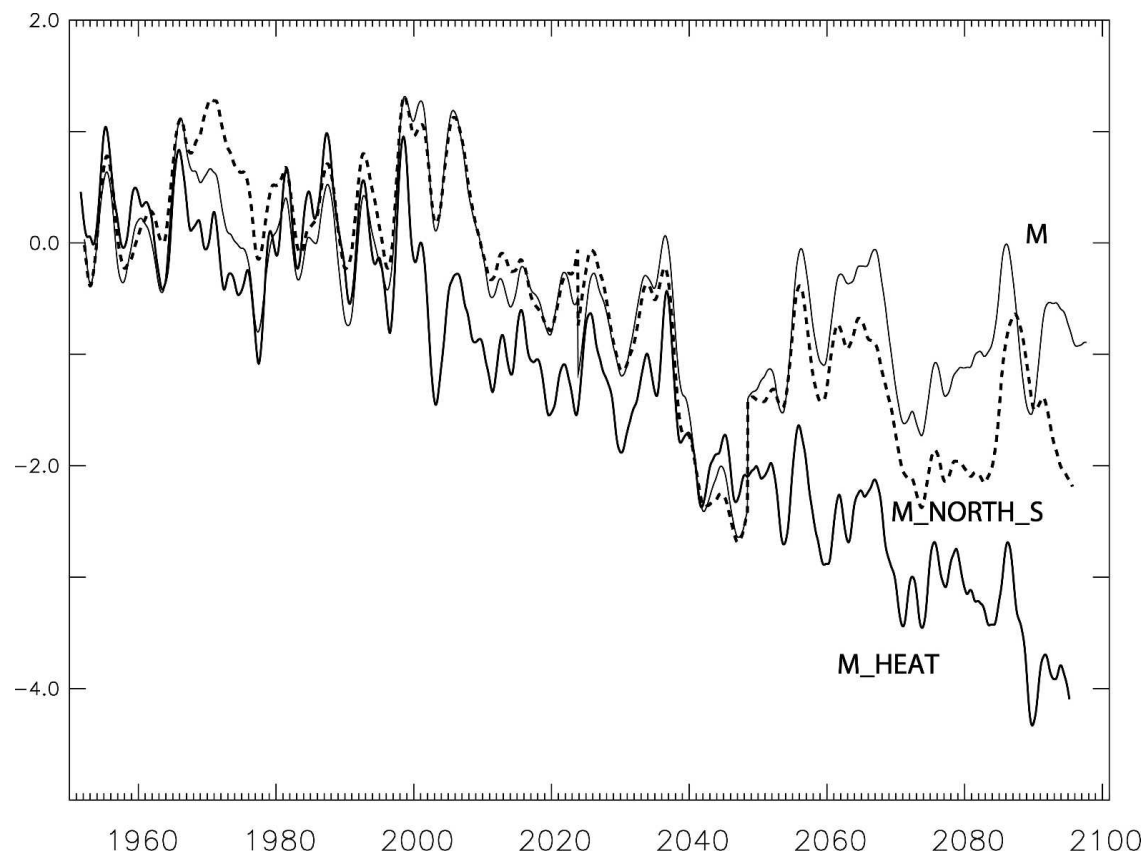

FIG. 3. The 2-yr running mean time series of anomalies in the maximum overturning of FLAME4/3 in experiments M_HEAT (thick line) and M_NORTH_S (dashed). The thin line is the response of experiment $\mathrm{M}(\mathrm{Sv})$.

dic Seas relative to the subpolar gyre for THC changes, we have performed further sensitivity experiments with the GFDL forcing. In experiment G_SURF the northern boundary condition is kept climatological, while the surface forcing includes the anthropogenic signal. The response is shown in Fig. 4 (dashed line). While the short-term variability up to a few years is comparable to the full forcing experiment $\mathrm{G}$, this experiment shows no

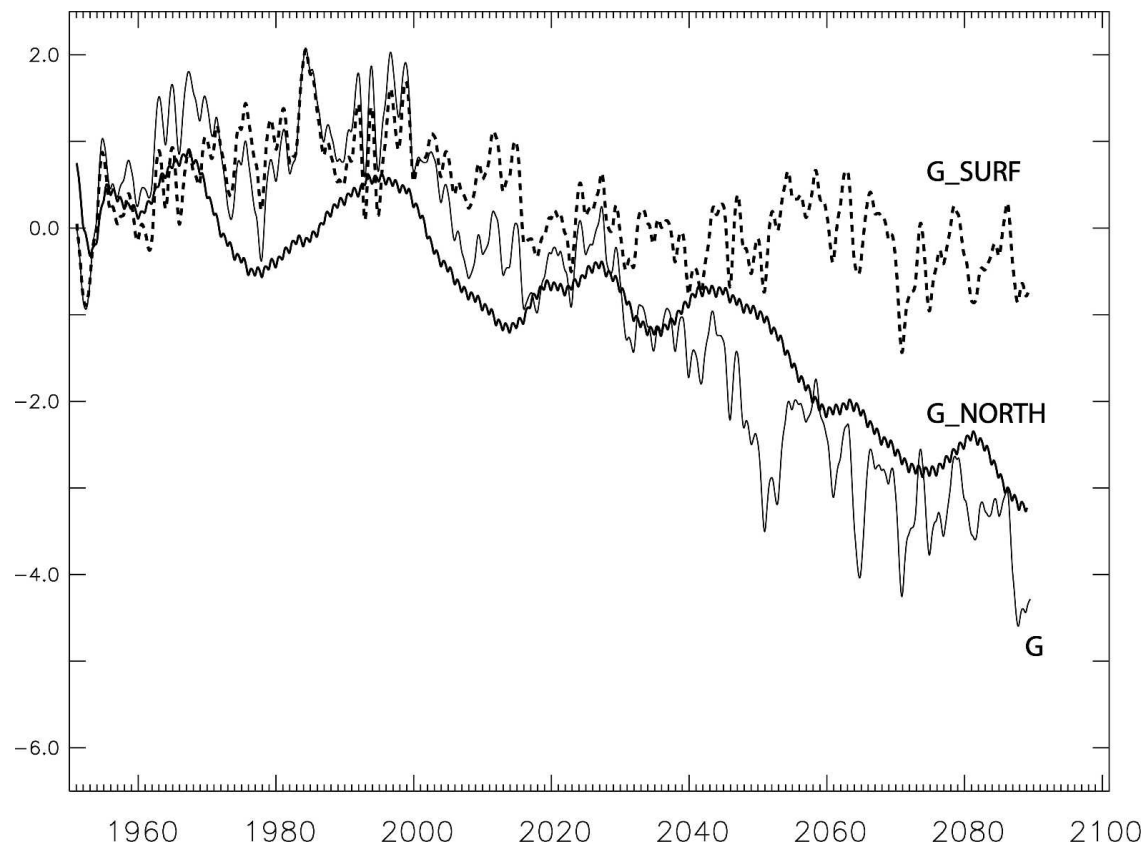

FIG. 4. Same as in Fig. 3, but for the anomalous overturning maximum of FLAME4/3 in experiments G_SURF (dashed) and G_NORTH (thick line). The thin line is the response of experiment $\mathrm{G}(\mathrm{Sv})$. 


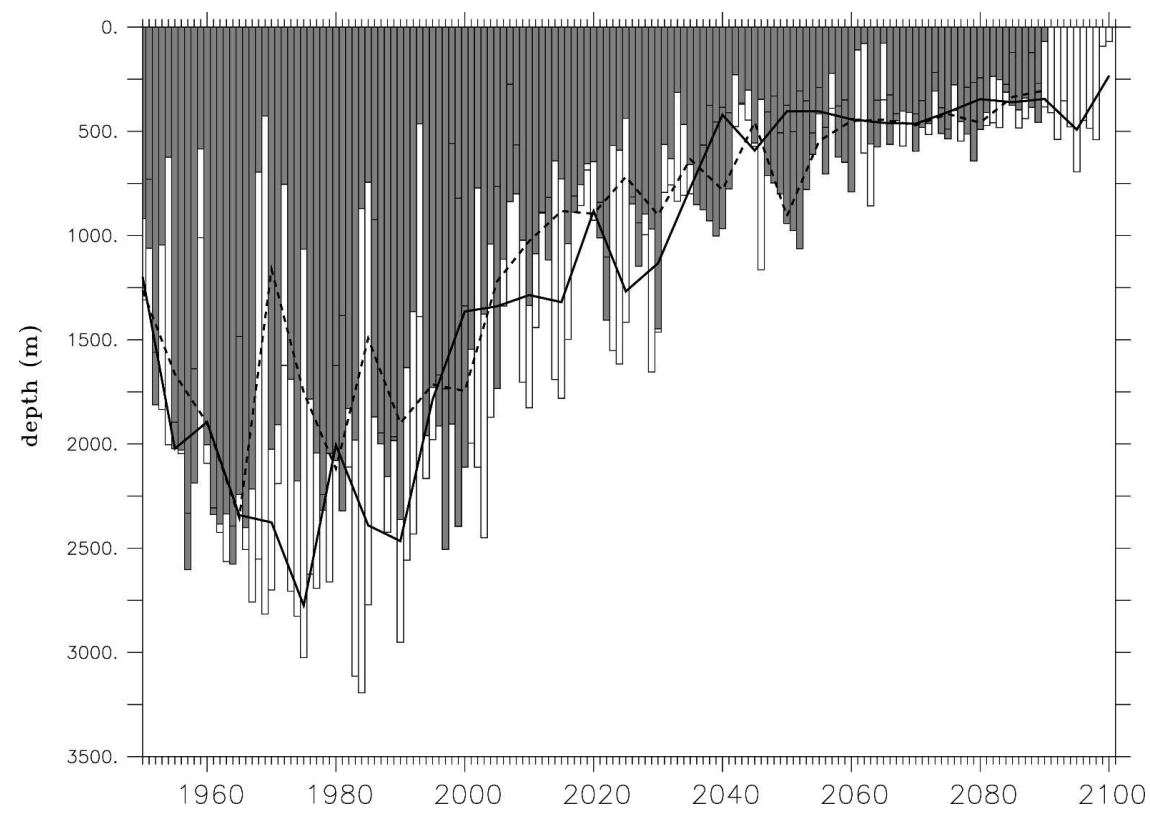

FIG. 5. Maximum winter [Jan-Mar (JFM)] depth of the mixed layer in the Labrador Sea between $56^{\circ}-60^{\circ} \mathrm{N}$ and $50^{\circ}-55^{\circ} \mathrm{W}$ in experiments $\mathrm{G}$ (gray) and $\mathrm{M}$ (white). Overlayed is the five-winter average of $\mathrm{G}$ (dashed) and $\mathrm{M}$ (line).

significant change in the overturning circulation and also little long-term variability. In contrast, experiment G_NORTH is driven by climatological surface forcing, but the northern boundary density changes are implemented (Fig. 4, thick line). In this experiment, both trend and interdecadel variability are almost totally reconstructed. The year-to-year variability within the subpolar gyre is missing, indicating that surface heat and momentum forcing are crucial on these time scales. The results are in line with the findings under MPI forcing: in both cases the densities in the outflow region of the Nordic Seas determine long-term variability and trend. If these densities remain unchanged (experiments M, M_HEAT_S, G_SURF), the overturning circulation does not weaken significantly.

\section{c. The Labrador Sea}

The regional model results allow us to look at the evolution of convection in the Labrador Sea, which is absent in both climate models. Figure 5 shows the time series of the winter mixed layer depth in the central Labrador Sea for both experiments G and M. In both integrations, during the second half of the twentieth century, the wintertime cooling facilitates deep convection down to $2000 \mathrm{~m}$ and more. In experiment $\mathrm{G}$ (dashed line), after year 2005 the mixed layer depth decreases significantly and while convection still takes place, it is rarely deeper than $800 \mathrm{~m}$ during the twentyfirst century. In experiment $\mathrm{M}$ (full line), shallowing of the winter mixed layer sets in at the end of the twentieth century, and after 2040, deep convection is more or less suppressed.

To analyze the reason for this response, Fig. 6 shows the time series of surface salinity (Fig. 6a), temperature (Fig. 6b), and resulting density (Fig. 6c) in the central Labrador Sea for both experiments. While in experiment $G$ the surface waters are 0.15 psu fresher at the end of the integration period, in experiment $\mathrm{M}$ surface salinity increases substantially after the year 2030 . This gain in surface salinity (around 0.08 psu at the end of the century) can be traced back to anomalous lateral salt transports. The Labrador Sea region is affected a few years later than the Denmark Strait Overflow (cf. Fig. 2a).

Both experiments show a warming toward the end of the twenty-first century. The surface waters become about $2.5^{\circ} \mathrm{C}$ warmer in experiment $\mathrm{M}$ and about $1.3^{\circ} \mathrm{C}$ warmer in experiment $\mathrm{G}$. The resulting surface density (Fig. 6c) in experiment $\mathrm{M}$ is $0.25 \mathrm{~kg} \mathrm{~m}^{-3}$ lower in 2030 and continues to slowly decrease throughout the remainder of the experiment. The density is reduced mainly due to the temperature increase, before a compensation between warmer and saltier water takes place also in the Labrador Sea. In experiment G, more moderate warming but also freshening lead to a rela- 

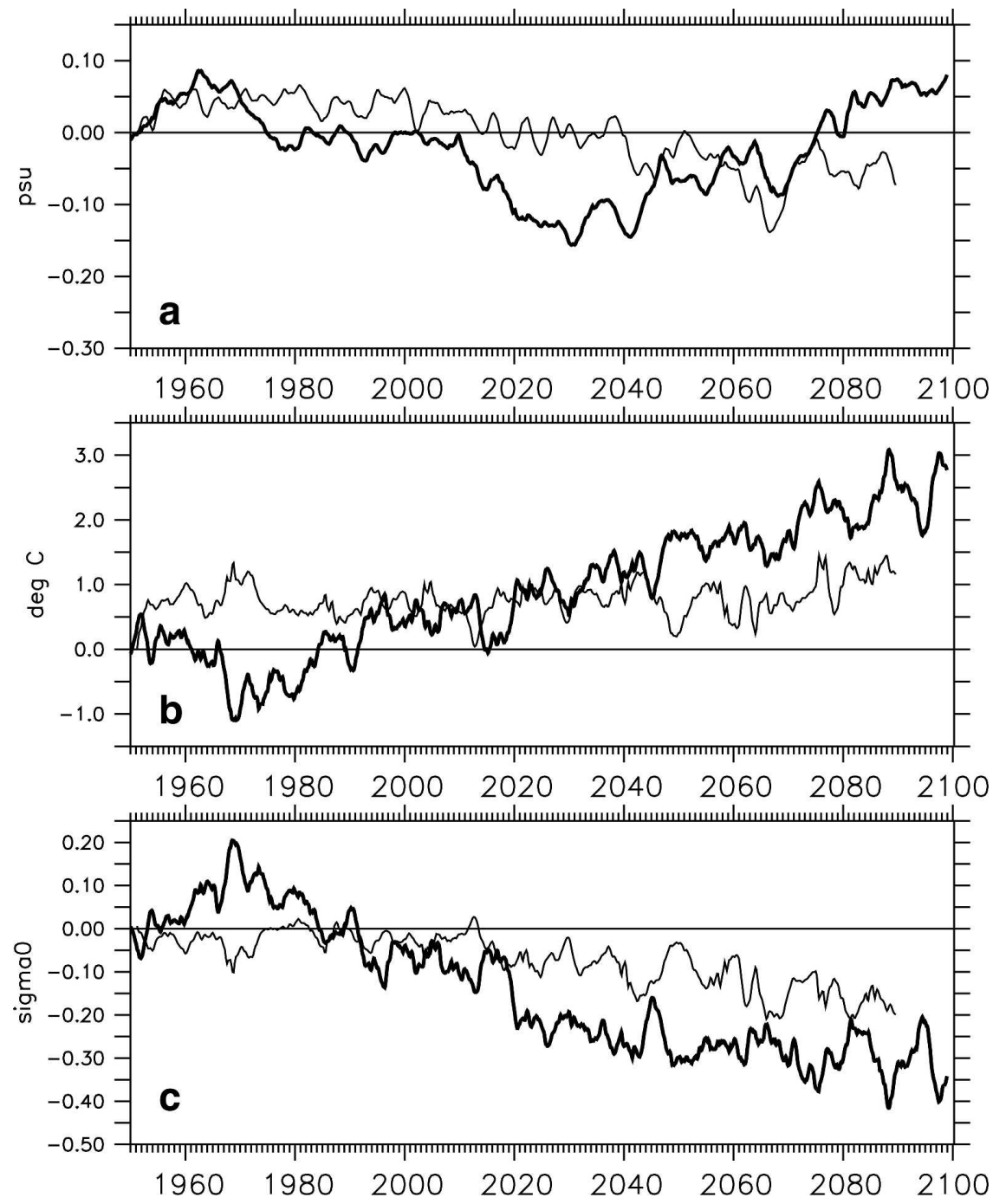

FIG. 6. Same as in Fig. 2, but for (c) $\sigma_{\text {Theta }}$ at the surface in the Labrador Sea averaged between $56^{\circ}-60^{\circ} \mathrm{N}$ and $50^{\circ}-55^{\circ} \mathrm{W}$ in experiments $\mathrm{M}$ (thick line) and $\mathrm{G}$ (thin line).

tively slow reduction of surface density with strong variability. However, at the end of the integration period, the annual mean density reduction is about $70 \%$ of that in experiment $\mathrm{M}$.

The shutdown of Labrador Sea convection in experiment $\mathrm{M}$ has a moderate effect on the meridional overturning. Between the years 2030 and 2050 a reduction of the overturning index of about $1 \mathrm{~Sv}$ can be seen (Fig. 1). Due to the stronger density variability in the overflow region in experiment G (Fig. 2c), the impact on the overturning index is not as obvious though likely of similar magnitude.

Note that both the $\mathrm{M}$ and the $\mathrm{G}$ experiments show a similar decrease of deep convection in the Labrador Sea, although the response of the overturning circulation differs fundamentally. Hence, one can conclude that Labrador Sea convection, while dominating the year-to-year variability of the overturning circulation, has only a limited influence on its long-term trend.

\section{Summary and conclusions}

The purpose of this study was to determine to what extent deficiencies in the representation of ocean processes may be responsible for the widely diverging response of the thermohaline circulation in global warming simulations with coupled climate models. We have performed sensitivity experiments with a regional ocean model that has been driven with the forcing anomalies from the global warming integrations of two coupled models under the Intergovernmental Panel on Climate Change (IPCC) IS92a scenario from 1950 to 
2090 (GFDL) respective to 2100 (MPI). The two coupled models experience rather different evolution of the overturning circulation, which stays almost constant in the MPI model and substantially declines in the GFDL model. The regional ocean model used in the present study is well tested with respect to its mean circulation and interannual variability, and in particular simulates the magnitude and location of water mass transformation processes-which are important for the meridional overturning-more accurately than the ocean components of either climate model. The reason must be found in the higher horizontal and vertical resolution and more realistic surface fluxes of the ocean model. Additionally, temperatures and salinities at the northern boundary are prescribed by climatological observations, to ensure that characteristics of deep-water masses in the model agree with observations.

An important result of this study is that the meridional overturning response of the regional model corresponds rather closely to that of the respective coupled simulation; that is, it remains constant when driven with the forcing from the MPI model, and declines when driven with the GFDL forcing. These findings suggest that a detailed representation of the ocean circulation in the subpolar region, while obviously desirable, may not be critical for the simulation of the overall THC changes in a global warming scenario. Specifically, our results suggest that the large spread in the THC evolution reported by IPCC is unlikely to be caused by misrepresentation of those ocean processes that occur within the bounds of the regional model, in particular the water mass transformation processes in the subpolar North Atlantic. It follows that the causes are likely to be either in the ocean outside the region of the regional model (in particular the Northern Seas), and/or in the air-sea interactions and in the atmospheric component of the coupled models.

Sensitivity experiments were undertaken to delineate the relevant mechanisms that govern the THC response. These experiments have confirmed that an important influence on the THC response to global warming is the density of the intermediate waters in the Greenland-Iceland-Norwegian (GIN) Seas, which in turn determines the density of the North Atlantic Deep Water. In contrast, changes in the air-sea heat and freshwater fluxes over the subpolar North Atlantic are only of moderate importance, and mainly determine the interannual-decadal variability of THC. This result is in line with several previous modeling studies (e.g., Döscher and Redler 1997).

The fact that the density of the overflow water is closely related to the overall THC strength makes it a very suitable parameter to monitor THC changes. So far, the observed variations of the density appear to be rather small. Dickson et al. (2002) reported a freshening of the Denmark Strait Overflow between 1965 and 2002 of $0.03-0.04 \mathrm{psu}$, with a variability of $0.02 \mathrm{psu}$. Experiment $\mathrm{G}$ has a comparable trend but much higher variability (cf. section $3 b$ ), while experiment $M$ has no clear trend or comparable variability. In both models, substantial changes that affect the overturning transport occur only after year 2000.

Convection in the Labrador Sea is a source of an important water mass, and its changes are connected with the variability of the THC. That process is simulated fairly well in the regional model but not in the coupled models (convection occurs in the Irminger Sea in the GFDL model, and in the MPI model there is no convection in the subpolar gyre). Hence, we can expect a more accurate evolution of future Labrador Sea convection from the regional model experiments. An interesting result is that as a result of changing surface fluxes the convection ceases by about 2030 (Fig. 5) under both forcings, that is, even in a situation where the overall THC is stable as in the MPI model. This result suggests that the eventual breakdown of the convection, while having only a small effect on the overall overturning transport, may be a rather plausible scenario. Strong convection and deep-water formation has been observed in the early 1990s (e.g., Lilly et al. 1999; Rhein et al. 2002), while between 1998 and 2001 no significant renewal of Labrador Sea Deep Water took place, neither in the central Labrador Sea nor along the boundary currents (Stramma et al. 2004). These observations confirm that deep convection in the Labrador Sea is very sensitive to surface forcing. Note however that the reduction of convection observed since 1994 are connected to changes in the North Atlantic Oscillation index, and do not necessarily indicate an early sign of global warming.

Note that there are several caveats, which may limit the ability of the regional model to simulate the THC evolution, and hence the validity of our conclusions.

First, our model is regional, and the forcing at the boundaries is implemented such that the global model can influence the regional model but not vice versa. To the extent that these interactions are important, the simulations with the regional model will suffer from the deficits in the boundary forcing data generated by the coupled models. This is most likely important for the Nordic Seas where the density of the overflow water is set, whereas the anomalies along the boundaries in the Southern Ocean appear to be much less important.

Like both climate models, the regional ocean model 
is not eddy resolving, and hence the influence of mesoscale eddies on the response is not represented beyond the parameterization. However, in sensitivity studies under idealized forcing, experiments with an eddy-permitting version of the regional model reveal a similar response of the overturning circulation.

A further caveat comes from the fact that the regional model is ocean only. The anomalous surface freshwater and momentum flux patterns are prescribed independently of the oceanic state, and the anomalous surface heat flux pattern depends on SST relative to restoring temperature changes. Hence, ocean-atmosphere interactions cannot be taken into account, and the fluxes diagnosed from the climate models-which could indeed be the result of coupled interactions-are forcing the higher-resolved ocean model. Whether the ocean variability is predominantly forced by the atmosphere or the result of a coupled air-sea interactions, is still an open question (e.g., Kushnir and Held 1996; Timmermann et al. 1998). By integrating an ocean component in a coupled and an uncoupled version, Delworth and Greatbatch (2000) diagnosed that interactions were only to a small degree responsible for oceanatmosphere fluxes, suggesting that this factor may be of less importance.

Acknowledgments. We thank Mojib Latif and Keith Dixon for making the forcing data of their global model integrations available to us, and three anonymous reviewers for their constructive comments. This is a contribution of "Sonderforschungsbereich 460: Dynamics of Thermohaline Circulation Variability," which is funded by the Deutsche Forschungsgemeinschaft.

\section{REFERENCES}

Bacher, A., J. Oberhuber, and E. Roecker, 1998: ENSO dynamics and seasonal cycle in the tropical Pacific as simulated by the ECHAM4/OPYC3 coupled general circulation model. Climate Dyn., 14, 431-450.

Boyer, T., and S. Levitus, 1997: Objective Analyses of Temperature and Salinity for the World Ocean on a $1 / 4^{\circ}$ Grid. NOAA Atlas NESDIS 11, 64 pp.

Delworth, T. L., and R. J. Greatbatch, 2000: Multidecadal thermohaline circulation variability driven by atmospheric surface flux forcing. J. Climate, 13, 1481-1494.

— , R. Stouffer, K. Dixon, M. Spelman, T. Knutson, A. Broccoli, P. Kushner, and R. Wetherald, 2002: Review of simulations of climate variability and change with the GFDL R30 coupled climate model. Climate Dyn., 19, 555-574.

Dickson, B., I. Yashayaev, J. Meincke, B. Turrell, S. Dye, and J. Holfort, 2002: Rapid freshening of the deep North Atlantic over the past four decades. Nature, 416, 832-837.

Dickson, R. R., E. M. Gmitrowicz, and A. J. Watson, 1990: Deepwater renewal in the northern North Atlantic. Nature, 344, $848-850$.
Dixon, K. W., T. L. Delworth, M. J. Spelman, and R. J. Stouffer, 1999: The influence of transient surface fluxes on North Atlantic overturning in a coupled GCM climate change experiment. Geophys. Res. Lett., 26, 2749-2752.

, T. Knutson, M. J. Spelman, and R. J. Stouffer, 2002: A comparison of climate change simulations produced by two GFDL coupled climate models. Global Planet. Change, 37, $81-102$.

Döscher, R., and R. Redler, 1997: The relative importance of northern overlow and subpolar deep convection for the North Atlantic thermohaline circulation. J. Phys. Oceanogr., 27, 1894-1902.

_ , and A. Beckmann, 2000: Effects of a bottom boundary layer parameterization in a coarse-resolution model of the North Atlantic Ocean. J. Atmos. Oceanic Technol., 17, 698-707.

Eden, C., and T. Jung, 2001: North Atlantic interdecadel variability: Oceanic response to the North Atlantic Oscillation (1865-1997). J. Climate, 14, 676-691.

_ , and J. Willebrand, 2001: Mechanism of interannual to decadal variability of the North Atlantic circulation. J. Climate, 14, 2266-2280.

Fischer, J., and F. A. Schott, 1997: Seasonal transport variability of the Deep Western Boundary Current in the Atlantic. J. Geophys. Res., 102, 27 751-27 769.

Gent, P., 2001: Will the North Atlantic Ocean thermohaline circulation weaken during the 21st century? Geophys. Res. Lett., 28, 1023-1026.

— lation models. J. Phys. Oceanogr., 20, 150-155.

Haney, R., 1971: Surface thermal boundary conditions for ocean circulation models. J. Phys. Oceanogr., 1, 241-248.

Haywood, J. M., D. L. Roberts, A. Sligo, J. M. Edwards, and K. P. Shine, 1997: General circulation model calculations of the direct radiative forcing by anthropogenic sulfate and fossilfuel soot aerosol. J. Climate, 10, 1562-1577.

Houghton, J. T., B. A. Callander, and S. K. Varney, Eds., 1992: Climate Change 1992: The Supplementary Report to the IPCC Scientific Assessment. Cambridge University Press, 205 pp.

—, Y. Ding, D. J. Griggs, M. Noguer, P. J. van der Linden, and D. Xiaosu, Eds., 2001: Climate Change 2001: The Scientific Basis. Cambridge University Press, 944 pp.

Jia, Y., 2002: Ocean heat transport and its relationship to ocean circulation in CMIP coupled models. Climate Dyn., 20, 153174.

Kushnir, Y., and I. Held, 1996: Equilibrium atmospheric response to North Atlantic SST anomalies. J. Climate, 9, 1208-1220.

Latif, M., E. Roecker, U. Mikolajewicz, and V. Voss, 2000: Tropical stabilization of the thermohaline circulation in a greenhouse warming simulation. J. Climate, 13, 1809-1813.

Levitus, S., and T. Boyer, 1994: Temperature. Vol. 4, World Ocean Atlas 1994, NOAA Atlas NESDIS 4, 117 pp.

Lilly, J. M., P. B. Rhines, M. Visbeck, R. Davis, J. R. N. Lazier, F. Schott, and D. Farmer, 1999: Observing deep convection in the Labrador Sea during winter 1994/95. J. Phys. Oceanogr., 29, 2065-2098.

Manabe, S., and R. Stouffer, 1994: Multiple-century response of a coupled ocean-atmosphere model to an increase of the atmospheric carbon dioxide. J. Climate, 7, 5-23.

Oberhuber, J., E. Roecker, A. Bacher, M. Esch, and M. Latif, 1998: Predicting the '97 El Niño event with a global climate model. Geophys. Res. Lett., 25, 2273-2276. 
Pacanowski, R., 1995: MOM 2 documentation. Users' guide and reference manual, GFDL Ocean Group Tech. Rep. 3, 329 pp.

—, K. Dixon, and A. Rosati, 1991: Ocean model users' guide version 1. GFDL Ocean Group Tech. Rep. 2, 44 pp.

Rhein, M., and Coauthors, 2002: Labrador Sea Water: Pathways, CFC-inventory and formation rates. J. Phys. Oceanogr., 32, 648-665.

Stevens, D., 1990: On open boundary conditions for three dimensional primitive equation ocean circulation models. Geophys. Astrophys. Fluid Dyn., 51, 103-133.
Stramma, L., D. Kieke, M. Rhein, F. Schott, I. Yashayaev, and K. Koltermann, 2004: Deep Water changes at the western boundary of the subpolar North Atlantic during 1996 and 2001. Deep-Sea Res., 51, 1033-1056.

Thorpe, R., J. Gregory, T. Johns, R. Wood, and J. Mitchell, 2001: Mechanisms determining the Atlantic thermohaline circulation response to greenhouse gas forcing in a non-fluxadjusted coupled climate model. J. Climate, 14, 3102-3116.

Timmermann, A., M. Latif, R. Voss, and A. Grötzner, 1998: Northern Hemispheric interdecadal variability: A coupled air-sea mode. J. Climate, 11, 1906-1931. 